\title{
Heat discharge estimation using satellite remote sensing data on the Iwodake volcano in Satsuma-Iwojima, Japan
}

\author{
Minoru Urai \\ Geological Survey of Japan, AIST, Central 7, Higashi 1-1-1, Tsukuba, Ibaraki 305-8567, Japan \\ (Received April 6, 2000; Revised August 30, 2001; Accepted October 6, 2001)
}

\begin{abstract}
A series of heat discharges from the Iwodake volcano was estimated using nighttime Landsat TM data. The data includes heat discharge only from steaming ground and excludes fumarole, hot spring activities and others. The heat discharge was estimated at 40-80 MW from 1989 to 1993 using temperature distributions derived from Landsat TM band 6, and started to increase since 1995. From the error analysis, the true heat discharge will be in the range from $-60 \%$ to $+20 \%$ of the calculated discharge of this method. Two hot spots in the northeast to southwest direction correspond to the high temperature fumaroles seen in the temperature distributions derived from band 7 . A new hot spot corresponds to a new degassing vent has been observed on the southern end of the summit crater since January 1992, and expanded to the same size as the other two hot spots since December 1993.
\end{abstract}

\section{Introduction}

Remote sensing is useful for monitoring active volcanoes (Mouginis-Mark and Francis, 1992). For example, surface temperature monitoring of volcanoes is necessary to mitigate volcanic disasters and understand the volcanic eruption processes. In many cases, temperature observations from the surface and aircraft on active volcanoes are hazardous. Satellite remote sensing can be safety used for surface temperature monitoring. Kagiyama (1981) estimated heat discharges of 22 major volcanoes in Japan mainly using airborne thermal infrared images. Kaneko and Wooster (1999) found that a positive correlation between the fumarolically driven shortwave infrared flux and magma discharge rate at Unzen volcano. Urai (2000) pointed out the hot area detected by shortwave infrared imagery is closely related with the magma effusion rate at the Unzen volcano. Harris et al. (1999) estimated the heat discharge and magma circulation rate within the reservoir-conduit-lake system of lava lakes at Erebus, Erta'Ale and Pu'u 'O'o volcanoes with Landsat and field data.

Iwodake on Satsuma-Iwojima Island is one of the most active volcanoes in Japan, located south of Kagoshima, Japan (Fig. 1). Extensive degassing from the Iwodake summit crater has been reported by Hedenquist et al. (1994). This paper reports the heat discharge rate from Iwodake using Landsat TM data.

\section{Geologic Outline of Satsuma-Iwojima}

Satsuma-Iwojima is located on the northwest rim of the Kikai Caldera, which extends about $20 \mathrm{~km}$ east-west and 17 $\mathrm{km}$ north-south (Fig. 1). Most of the Kikai Caldera is occupied by sea (Ono et al., 1982). Shin-Iwojima, which is

Copy right(C) The Society of Geomagnetism and Earth, Planetary and Space Sciences (SGEPSS); The Seismological Society of Japan; The Volcanological Society of Japan; The Geodetic Society of Japan; The Japanese Society for Planetary Sciences. located $2 \mathrm{~km}$ east of Satsuma-Iwojima, is a new volcanic island formed by the volcanic activity during 1934-1935. There are two post-caldera cones in Satsuma-Iwojima. One is Inamuradake volcano that is the only basaltic post-caldela cone presently known in the Kikai Caldera. The other is Iwodake volcano having a steep rhyolite stratovolcano about $700 \mathrm{~m}$ high with a large crater at its summit. The volcano is a pile of thick lava flows and bedded coarse volcanic rocks, most of that are talus deposits, probably formed at the front of lava flow or lava dome. Many fumaroles are active around the summit crater and flank area. Some fumaroles have very high temperature, over $800^{\circ} \mathrm{C}$ (Shinohara et al., 1993). Silica stones formed by fumarolic alteration are found around the summit crater and other fumarole areas. Recently, Shinohara et al. (2002) found that fumarole activity and ground temperature in the summit crater started to decrease from 1997.

\section{Geothermal Heat Discharge Estimation from Satellite Remote Sensing}

An ideal thermal emitter, called a black body, is one that transforms heat energy into radiant energy according to Plank's function. Any body at a specific temperature emits radiation in accordance with its own characteristics. Any real material at the same temperature cannot emit thermally at a rate in excess of that of a blackbody. It is convenient to express the capability to emit radiation due to thermalenergy conversion as the ratio of the spectral exitance of a material to the spectral exitance of a blackbody at the same temperature. The ratio is called the spectral emissivity of the material. The upwelling radiance detected at the satellite level is the product of atmospheric transmittance, surface emissivity and Planck's function of surface temperature plus atmospheric radiance as shown below: 


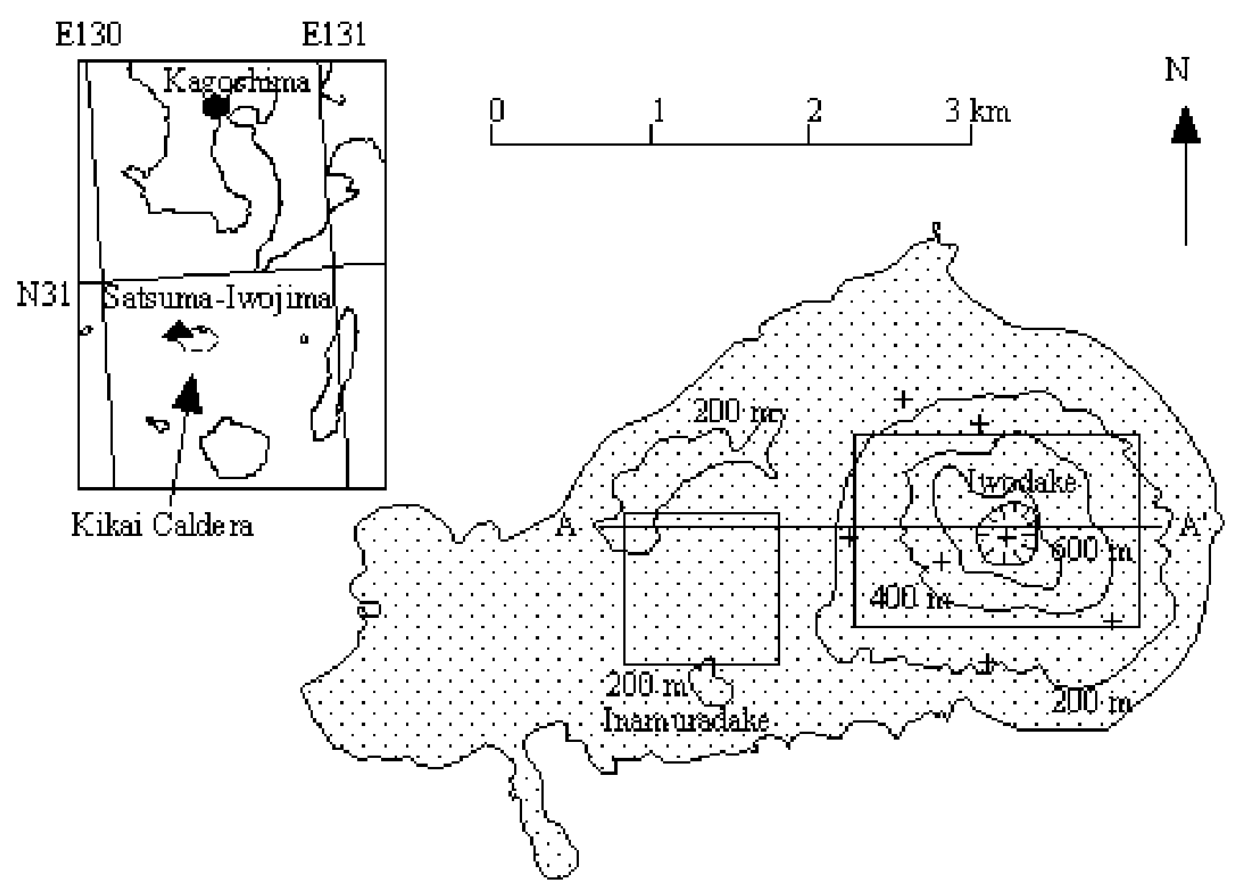

Fig. 1. Topographic map of Satsuma-Iwojima. Line A-A' is the temperature profile line for Fig. 2. The rectangle near the summit is the area that temperature distributions are calculated with Landsat TM band 7 and shown in Fig. 4. The square area near Inamuradake is selected as the geothermal normal area. The + symbol indicates the fumarole area.

$$
R_{\lambda}=\tau_{\lambda} \varepsilon_{\lambda} \frac{B(\lambda, T)}{\pi}+R_{\mathrm{atm}, \lambda},
$$

$R_{\lambda}$ : radiance at the satellite level $\left[\mathrm{W} \mathrm{m} \mathrm{m}^{-3} \mathrm{sr}^{-1}\right]$

$\tau_{\lambda}:$ atmospheric transmittance

$\varepsilon_{\lambda}$ : spectral emissivity of the radiating surface

$B(\lambda, T)$ : Plank's function $\left[\mathrm{W} \mathrm{m}^{-3}\right]=\frac{c_{1} \lambda^{-5}}{\exp \left(\frac{c_{2}}{\lambda T}\right)-1}$

$\lambda$ : wavelength $[\mathrm{m}]$

$T$ : surface temperature $[\mathrm{K}]$

$c_{1}: 3.742 \times 10^{-16}\left[\mathrm{~W} \mathrm{~m}^{2}\right]=2 \pi h c^{2}(h$ is Plank's constant and $c$ is speed of light)

$c_{2}: 0.0144[\mathrm{~m} \mathrm{~K}]=h c / k$ ( $k$ is Boltzmann's constant $)$

$R_{\text {atm }, \lambda}$ : atmospheric radiance $\left[\mathrm{W} \mathrm{m} \mathrm{m}^{-3} \mathrm{sr}^{-1}\right]$.

The first term of the Eq. (1) represents the radiance emitted by the earth's surface features and transmitted through the atmosphere up to the satellite sensor. The second term of the Eq. (1) represents the upwelling radiance emitted by the atmosphere towards the sensor. Eq. (1) can be rearranged to give $T$, thus

$$
T=\frac{c_{2}}{\lambda \ln \left(\frac{\tau_{\lambda} \varepsilon_{\lambda} c_{1} \lambda^{-5}}{\pi\left(R_{\lambda}-R_{\mathrm{atm}, \lambda}\right)}+1\right)} .
$$

In general, surface temperature varies with meteorological conditions, daytime solar radiation, thermal inertia, elevation and geothermal activity. If the temperature anomalies caused by geothermal activity are not large compared with other anomalies, these effects should be corrected. It is necessary to establish a thermal model of the earth's surface and collect ground observation data to correct meteorological, solar radiation, thermal inertia and elevation effects. For example, the temperature anomaly caused by elevation can be corrected if the digital terrain model is available as follows;

$$
T_{c}=T+d t E
$$

$T_{c}:$ altitude corrected surface temperature $[\mathrm{K}]$

$E$ : elevation $[\mathrm{m}]$

$d t$ : temperature correction coefficient $\left[\mathrm{K} \mathrm{m}^{-1}\right]$.

If only geothermal effects cause the temperature anomalies, geothermal heat discharge from the steaming ground can be calculated according to Sekioka and Yuhara (1974) with the following equation,

$$
Q=K \sum_{\Delta T>T_{t}} \Delta T \cdot S,
$$

$Q$ : geothermal heat discharge [W]

$K$ : meteorological constant $\left[\mathrm{W} \mathrm{m} \mathrm{m}^{-2} \mathrm{~K}^{-1}\right]$

$S$ : area that surface temperature anomaly is $\Delta T\left[\mathrm{~m}^{2}\right]$

$\Delta T$ : temperature anomaly $[\mathrm{K}]=T_{c}-T_{0 c}$

$T_{t}$ : threshold temperature $[\mathrm{K}]$

$T_{0 c}$ : altitude corrected surface temperature in geothermal normal point $[\mathrm{K}]=T_{0}-d t E_{0}$.

\section{Heat Discharge Estimation Using Landsat TM Data}

The Landsat 5, which is an earth observation satellite, can observe the entire earth except for the polar regions every 16 days. The Thematic Mapper (TM), which is one of the sensors onboard the Landsat 5, has seven spectral bands covering the visible to thermal infrared region (USGS and NOAA, 1984).

Data acquired during the nighttime are used for heat discharge estimation to avoid the sun illumination effects. The Landsat 5 observed Satsuma-Iwojima 75 times at night from 


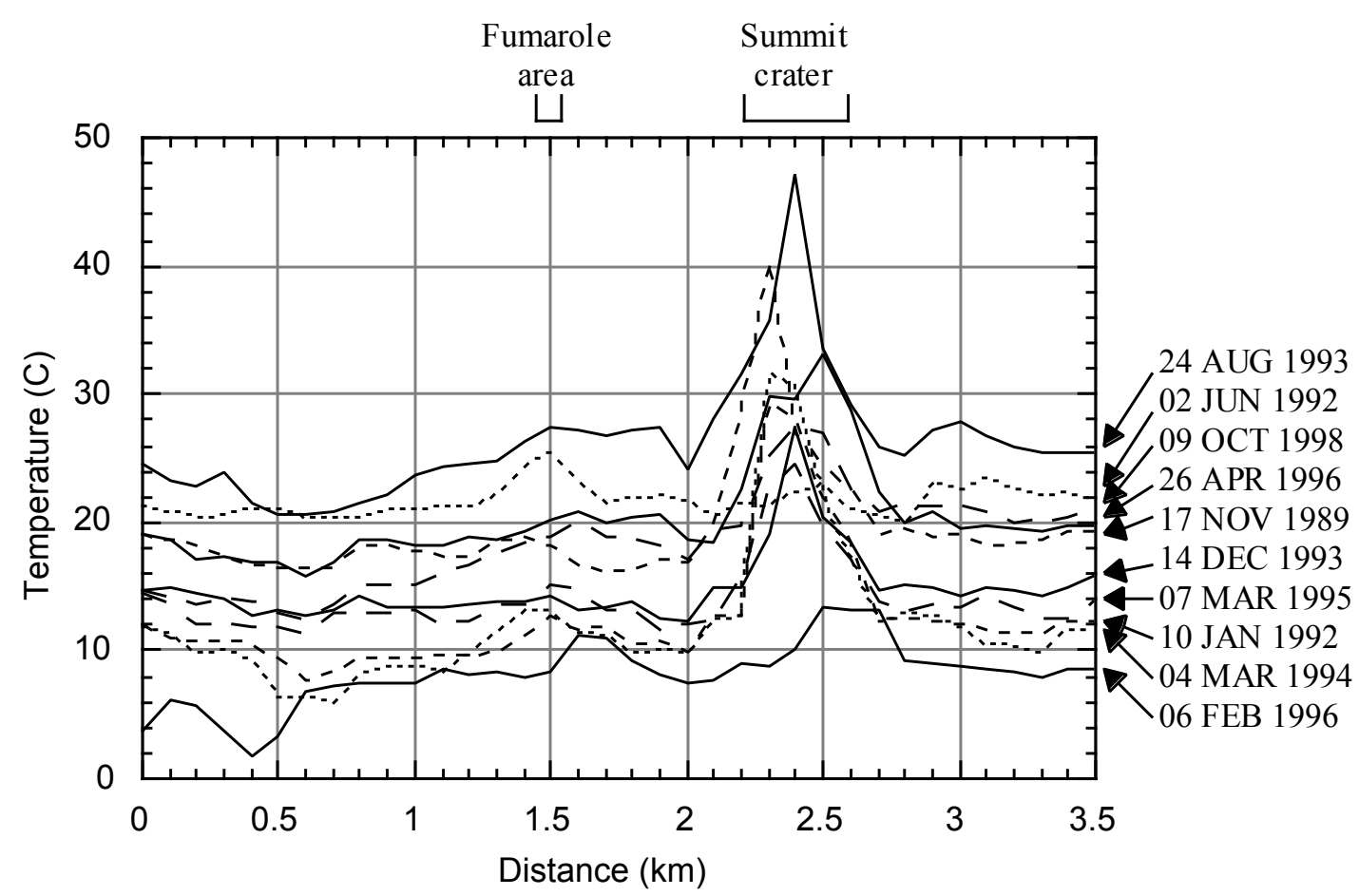

Fig. 2. Surface temperature profile derived from Landsat TM band 6 along the line A-A' in Fig. 1. The altitude correction was applied.

1984 to 1999 , and took ten cloud free and partly cloud covered images.

\subsection{Atmospheric transmission, radiance and spectral emissivity}

Atmospheric transmission and radiance were calculated by MODTRAN computer code (Berk et al., 1989) with an atmosphere model based on the daily rawinsonde sounding taken at the Kagoshima Meteorological Observatory approximately $90 \mathrm{~km}$ north of Satsuma-Iwojima. The amount of water vapor is the most critical parameter for the calculations in the thermal infrared regions. Altitude, temperature and humidity of Standard Pressure Levels at altitudes up to $30 \mathrm{~km}$, which are stored on CD-ROMs published by the Japan Meteorological Agency (1996a, b, c, d and 1999), were combined with the MODTRAN standard model for the MODTRAN calculations. The rawinsonde observations are conducted on 9:00 and 21:00 local time. The latter one was used for the atmospheric model because it's close to the Landsat TM observation time (about 21:50 local time). The calculated atmospheric transmission and radiance at a wavelength of $11.45 \mu \mathrm{m}$, which is the band center of the Landsat TM thermal band (band 6), are shown in Table 1. The atmospheric transmission is high in winter, more than 0.9 and low in summer, less than 0.7 . The atmospheric radiance is high in summer, more than $2 \times 10^{6} \mathrm{~W} \mathrm{~m}^{-3} \mathrm{sr}^{-1}$, which is about one quarter of the blackbody radiance at $20^{\circ} \mathrm{C}$.

The spectral emissivity of rhyolite is about 0.9 (Vincent et al., 1975) at $11.45 \mu \mathrm{m}$ which is the band center of the Landsat TM thermal band (band 6).

\subsection{Heat discharge estimation from 1989 to 1996}

The nearest-neighbor resample image of Landsat TM was first geometrically corrected to fit the 1:25,000 scale map with ground control points (GCPs), and converted to radi-
Table 1. Calculation of atmospheric transmission and radiance at a wavelength of $11.45 \mu \mathrm{m}$ with MODTRAN based on the daily rawinsonde sounding taken at the Kagoshima Meteorological Observatory.

\begin{tabular}{ccc}
\hline \multicolumn{1}{c}{ Date } & $\begin{array}{c}\text { Atmospheric } \\
\text { transmission }\end{array}$ & $\begin{array}{c}\text { Atmospheric radiance } \\
{\left[10^{5} \mathrm{~W} \mathrm{~m}^{-3} \mathrm{sr}^{-1}\right]}\end{array}$ \\
\hline 17 NOV 1989 & 0.945 & 3.12 \\
10 JAN 1992 & 0.923 & 3.90 \\
02 JUN 1992 & 0.692 & 23.9 \\
24 AUG 1993 & 0.646 & 29.4 \\
14 DEC 1993 & 0.926 & 4.02 \\
04 MAR 1994 & 0.935 & 3.38 \\
07 MAR 1995 & 0.943 & 3.07 \\
06 FEB 1996 & 0.966 & 1.34 \\
26 APR 1996 & 0.857 & 10.0 \\
09 OCT 1998 & 0.736 & 20.6 \\
\hline
\end{tabular}

ance using coefficients (Markham and Barker, 1986). The geometric accuracy seems to be about $120 \mathrm{~m}$, the same as the ground resolution of the thermal infrared band (band 6). The radiance of band 6 is converted to temperature by Eq. (2) using Table 1 for atmospheric transmission and radiance, and 0.9 as the surface emissivity.

Altitude correction was conducted with Eq. (3) based on the $50 \mathrm{~m}$ grid digital terrain model (Geographical Survey Institute, 1997). The temperature correction coefficients, which are calculated from the rawinsonde observation and shown in Table 2, were adapted. Figure 2 shows a series of altitude corrected temperature profiles of Satusma-Iwojima along with the line $\mathrm{A}-\mathrm{A}^{\prime}$ in Fig. 1. Large thermal anoma- 


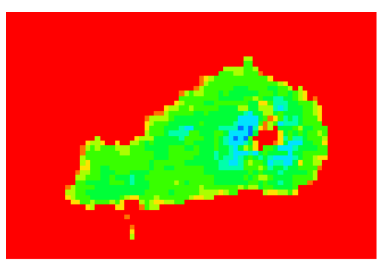

17NOV 1989

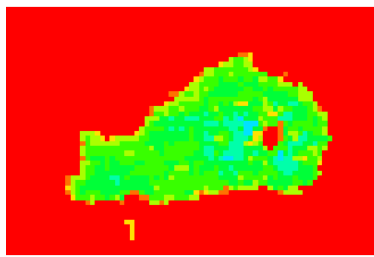

14DEC1993

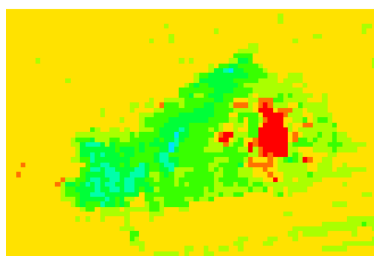

26APR1996

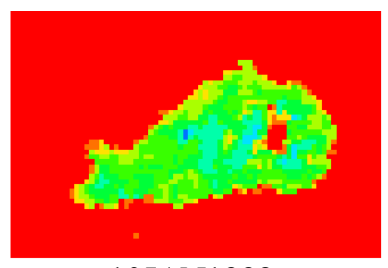

10JAN1992

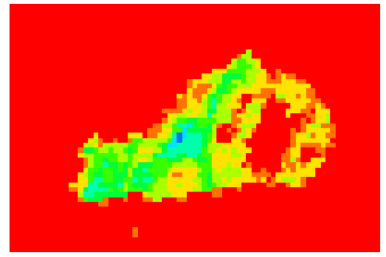

04MAR1994

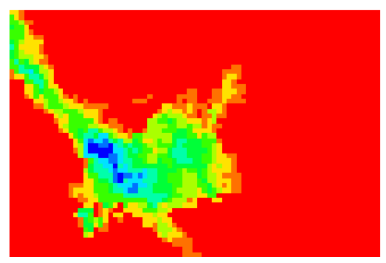

09OCT1998

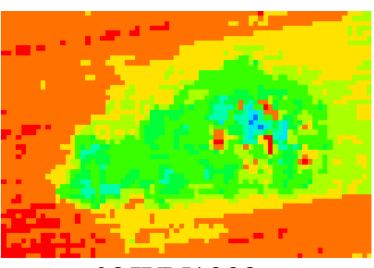

02JUN1992

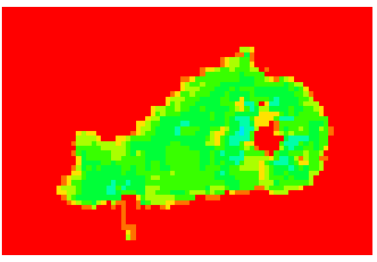

07MAR1995

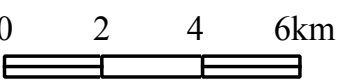

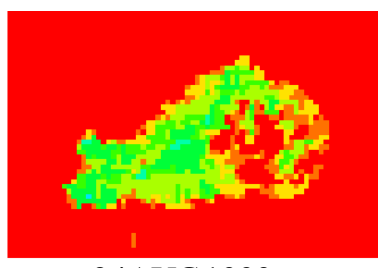

24AUG 1993

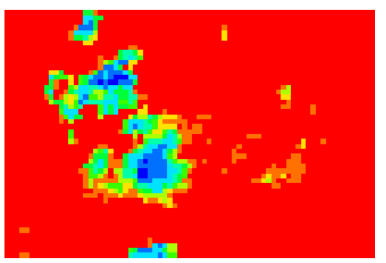

06FEB1996

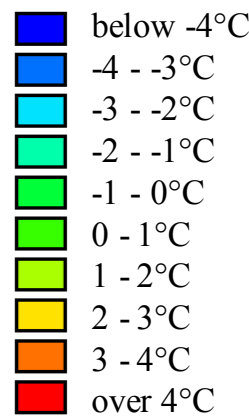

Fig. 3. Surface temperature distribution of Satuma-Iwojima derived from Landsat TM band 6 from November 1989 to October 1998.

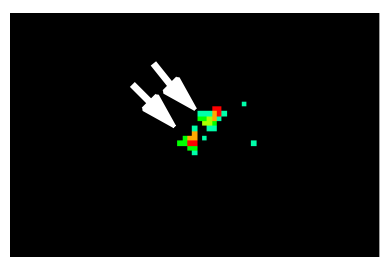

17NOV 1989

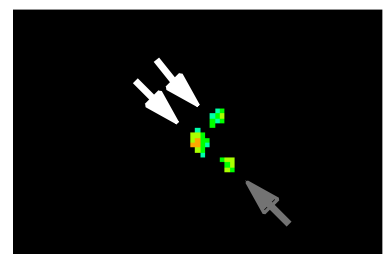

14DEC 1993

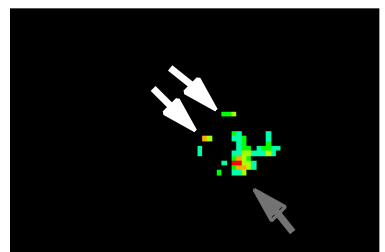

26APR1996

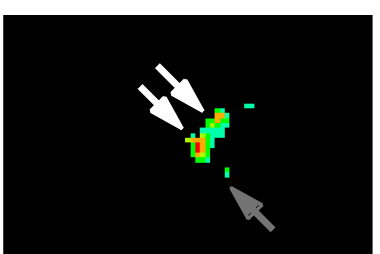

10JAN1992

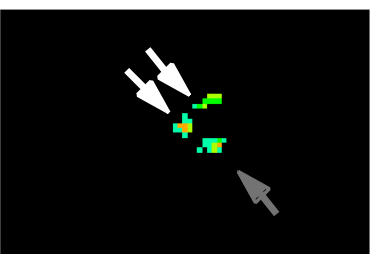

04MAR1994

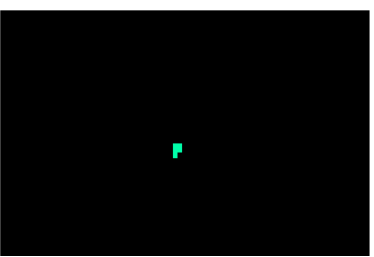

09OCT1998

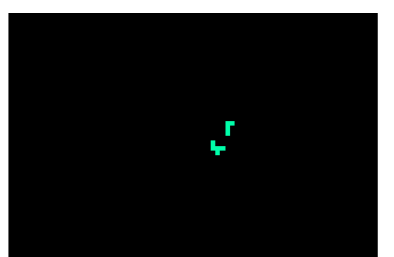

02JUN1992

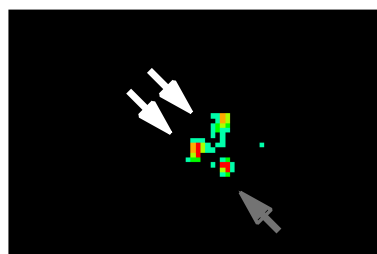

07MAR1995

0
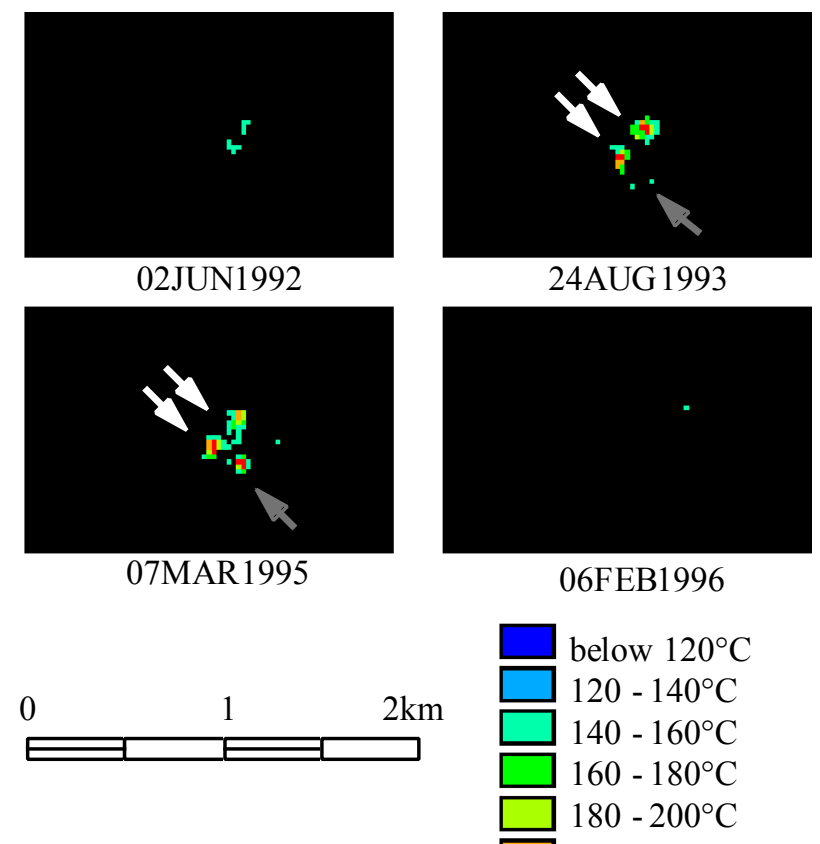

24AUG 1993

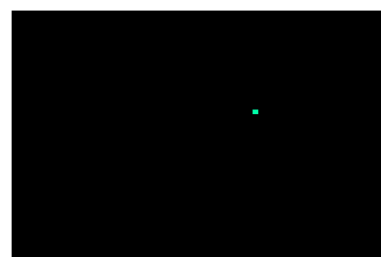

06FEB1996 below $120^{\circ} \mathrm{C}$

$120-140^{\circ} \mathrm{C}$

$140-160^{\circ} \mathrm{C}$

$160-180^{\circ} \mathrm{C}$

$180-200^{\circ} \mathrm{C}$

$200-220^{\circ} \mathrm{C}$

over $220^{\circ} \mathrm{C}$

below sensitivity

Fig. 4. Surface temperature distribution of Iwodake derived from Landsat TM band 7 from November 1989 to October 1998 . White arrows indicate stable hot spots and gray arrow indicates the new hot spot. Note: Scale is different in Fig. 3. The extent of temperature calculations is the rectangle near the summit in Fig. 1. Uniform atmospheric transmittance of 0.92 and surface emissivity of 0.7 are assumed. 
Table 2. Air cooling rates with elevation at the Kagoshima Meteorological Observatory calculated from the air temperature between the ground and $925 \mathrm{hPa}$ level.

\begin{tabular}{cc}
\hline Date & $\begin{array}{c}\text { Air temperature decrease } \\
\text { rates with elevation } \\
{\left[10^{-3} \mathrm{~K} \mathrm{~m}^{-1}\right]}\end{array}$ \\
\hline 17 NOV 1989 & 2.7 \\
10 JAN 1992 & 2.3 \\
02 JUN 1992 & 2.8 \\
24 AUG 1993 & 2.3 \\
14 DEC 1993 & 4.6 \\
04 MAR 1994 & 6.5 \\
07 MAR 1995 & 4.4 \\
06 FEB 1996 & 7.5 \\
26 APR 1996 & 6.0 \\
09 OCT 1998 & 6.8 \\
\hline
\end{tabular}

lies, over $10^{\circ} \mathrm{C}$, are found at the summit crater of Iwodake except for the observations on June 2, 1992 and February 6, 1996. A small anomaly is found on the flank near the 1.5 $\mathrm{km}$ point corresponding to a fumarole. The diameter of the temperature anomaly corresponding to the summit crater is about $700 \mathrm{~m}$, which is larger than the crater. The temperature variations except for the geothermal area are small, less than $\pm 3^{\circ} \mathrm{C}$.

A series of temperature distributions with the altitude corrected and geothermal normal temperature subtracted is shown in Fig. 3. A square area near Inamuradake was selected as the geothermal normal area and is shown in Fig. 1. The average temperatures and standard deviations of the geothermal normal area are shown in Table 3. A small standard deviation means that temperature difference caused by meteorological conditions, daytime solar radiation and thermal inertia is small. Because clouds covered some parts of Satsuma-Iwojima, a large standard deviation was found in the geothermal normal area on February 6, 1996. Heat discharge from Iwodake was calculated with Eq. (4) for six reliable temperature distributions that have standard deviations less than $1.0^{\circ} \mathrm{C}$. The meteorological constant $\mathrm{K}$ was assumed as $34 \mathrm{~W} \mathrm{~m}^{-2} \mathrm{~K}^{-1}$, which is an average of the observation values of other volcanoes (Sekioka et al., 1978). Following Kagiyama et al. (1979), the threshold temperature was determined as $3 \mathrm{~K}$, which is approximately three times the standard deviation of the geothermal normal area.

The heat discharge from Iwodake was 40-80 MW from 1989 to 1993 and started to increase since 1995 (Table 4). Matsushima (2001) conducted a ground based thermal infrared survey and estimated that the heat discharge from a part of the summit crater, which is visible from a point on the southwest rim of the summit crater, was $47 \mathrm{MW}$ in October, 1996. Although this survey only covers a part of the thermal anomaly area and the time is not the same, this estimate is consistent with the heat discharge calculated from Landsat TM.

Shinohara et al. (2002) found that fumarole activity and
Table 3. Average temperatures and standard deviations of the geothermal normal area.

\begin{tabular}{ccc}
\hline Date & $\begin{array}{c}\text { Average } \\
\text { temperature }\left({ }^{\circ} \mathrm{C}\right)\end{array}$ & $\begin{array}{c}\text { Standard } \\
\text { deviation }\left({ }^{\circ} \mathrm{C}\right)\end{array}$ \\
\hline 17 NOV 1989 & 17.6 & 0.52 \\
10 JAN 1992 & 10.4 & 0.92 \\
02 JUN 1992 & 20.6 & 0.47 \\
24 AUG 1993 & 21.5 & 1.04 \\
14 DEC 1993 & 14.0 & 0.60 \\
04 MAR 1994 & 8.6 & 1.72 \\
07 MAR 1995 & 12.6 & 0.56 \\
06 FEB 1996 & 4.1 & 3.17 \\
26 APR 1996 & 17.9 & 0.87 \\
09 OCT 1998 & 13.2 & 1.03 \\
\hline
\end{tabular}

Table 4. Heat discharge rate calculated from surface temperature distribution derived from Landsat TM band 6.

\begin{tabular}{cc}
\hline Date & $\begin{array}{c}\text { Heat discharge rate } \\
{\left[10^{6} \mathrm{~W}\right]}\end{array}$ \\
\hline 17 NOV 1989 & 49 \\
10 JAN 1992 & 77 \\
02 JUN 1992 & 38 \\
14 DEC 1993 & 42 \\
07 MAR 1995 & 94 \\
26 APR 1996 & 230 \\
\hline
\end{tabular}

ground temperature in the summit crater started to decrease from 1997. There is no Landsat TM nighttime data available after 1997. The heat discharge may have started to increase from 1995 and then decrease from 1997.

\subsection{Error analysis}

Sekioka et al. (1978) estimated that calculated discharge contains an error up to $20 \%$ for five observation values at three geothermal areas in Japan when the meteorological constant $\mathrm{K}$ is assumed as the constant.

Surface temperature distribution is not uniform in a $120 \mathrm{~m}$ by $120 \mathrm{~m}$ pixel of Landsat TM band 6, especially in geothermal areas. Remotely sensed surface temperature is not an average temperature of a pixel. For example, suppose we have a pixel composed of an area at $400^{\circ} \mathrm{C}$ that occupies $2 \%$ of the pixel and an area at $20^{\circ} \mathrm{C}$ that occupies $98 \%$ of the pixel. The remotely sensed temperature of the pixel based on the radiance at the center wavelength of Landsat TM band 6 is about $35.4^{\circ} \mathrm{C}$. The temperature anomaly from the background $\left(20^{\circ} \mathrm{C}\right)$ is about $15.4^{\circ} \mathrm{C}$, which is about $100 \%$ higher than the average temperature anomaly of $7.6^{\circ} \mathrm{C}$. According to the Eq. (4), the heat discharge is proportional to the temperature anomaly, the true heat discharge will be the range from $-50 \%$ to $+0 \%$ of the calculated one considering inhomogeneous temperature distribution.

On the other hand, small geothermal anomalies are ig- 
nored when the temperature anomaly of their pixel is less than the threshold temperature. The results underestimate the heat discharge. However it is difficult to quantify the effects.

The atmospheric transmittance, atmospheric radiance, spectral emissivity and others, which are sources of an error, are not discussed here. The true heat discharge will be in the range from $-60 \%$ to $+20 \%$ of the calculated discharge of this method considering constant $K$ value and inhomogeneous temperature distribution.

\section{Fumaroles Observed by Landsat TM Short- Wave Infrared Bands}

High temperature targets such as wild fires, volcanic activities and chimneys in iron works can be observed by Landsat TM short-wave infrared bands (Francis and Rothery, 1987). The ground resolution of the Landsat TM short-wave infrared bands is $30 \mathrm{~m}$, finer than band 6 . A series of surface temperatures are calculated by Eq. (2) for band 7 and shown in Fig. 4. Unlike band 6, band 7 is very sensitive to high temperature portions and has no sensitivity to the surface temperatures below $120^{\circ} \mathrm{C}$ in a pixel. For example, a high temperature fumarole of $600^{\circ} \mathrm{C}$ occupied only $0.1 \%$ of a pixel can be detect by band 7 (Rothery et al., 1988). Two hot spots in the northeast to southwest direction, which correspond to the high temperature fumaroles on the northern and western walls of the summit crater, are seen in all the temperature distributions except for the cloud covered scenes on February 6, 1996 and October 9, 1998. A new hot spot, which corresponds to a new degassing vent (Shinohara et al., 2002) inside the summit crater, has been observed on the southern end of the summit crater since January 1992, and expanded to the same size as the other two hot spots since December 1993.

\section{Conclusions}

A series of heat discharge from the Iwodake volcano was estimated using nighttime Landsat TM data. The heat discharge from Iwodake was estimated at 40-80 MW from 1989 to 1993 using temperature distributions derived from Landsat TM band 6, and started to increase since 1995. Two hot spots in the northeast to southwest direction, which correspond to the high temperature fumaroles, are seen in the temperature distributions derived from band 7. A new hot spot, which corresponds to a new degassing vent, has been observed on the southern end of the summit crater since January 1992, and increased to the same size as the other two hot spots since December 1993.

Acknowledgments. The CD-ROMs containing rawinsonde sounding data published by the Japan Meteorological Agency (JMA) are used in this work. The Earth Observation Company (EOSAT) and National Space Development Agency of Japan (NASDA) supported the author in acquiring the satellite data at a minimal cost. The author would like to thank two anonymous reviewers for helpful comments.

\section{References}

Berk, A., L. S. Bernstein, and D. C. Robertson, MODTRAN: A Moderate
Resolution Model for LOWTRAN 7, 38 pp., Geophysics Laboratory, GLTR-89-0122, Hanscom, 1989.

Francis, P. W. and D. A. Rothery, Using the Landsat Thematic Mapper to detect and monitor active volcanoes: An example from Lascar volcano, northern Chile, Geology, 15, 614-617, 1987.

Geographical Survey Institute, Digital Map $50 \mathrm{~m}$ Grid (Elevation) NIPPON III, CD-ROM, Geographical Survey Institute, Tsukuba, 1997.

Harris, A. J. L., L. P. Flynn, D. A. Rothery, C. Oppenheimer, and S. B. Sherman, Mass flux measurements at active lava lakes: Implication for magma recycling, J. Geophys. Res., 104, 7117-7136, 1999.

Hedenquist, J. W., M. Aoki, and H. Shinohara, Flux of volatiles and oreforming metals from the magmatic-hydrothermal system of Satsuma Iwojima volcano, Geology, 22, 585-588, 1994.

Japan Meteorological Agency, Aerological Data of Japan 1988-1990, CDROM, Japan Meteorological Agency, Tokyo, 1996a.

Japan Meteorological Agency, Aerological Data of Japan 1991-1994, CDROM, Japan Meteorological Agency, Tokyo, 1996b.

Japan Meteorological Agency, Aerological Data of Japan 1995, CD-ROM, Japan Meteorological Business Support Center, Tokyo, 1996c.

Japan Meteorological Agency, Aerological Data of Japan 1996, CD-ROM, Japan Meteorological Agency, Tokyo, 1996d.

Japan Meteorological Agency, Aerological Data of Japan 1998, CD-ROM, Japan Meteorological Business Support Center, Tokyo, 1999.

Kagiyama, T., Evaluation methods of heat discharge and their applications to the major active volcanoes in Japan, J. Volcanol. Geotherm. Res., 9, 87-97, 1981.

Kagiyama, T., K. Uhira, T. Watanabe, F. Masutani, and M. Yamaguchi, Geothermal survey of the volcanoes Kirishima, Bull. Earthq. Res. Inst., 54, 187-210, 1979 (in Japanese).

Kaneko, T. and M. J. Wooster, Landsat infrared analysis of fumarole activity at Unzen Volcano: time-series comparison with gas and magma fluxes, J. Volcanol. Geotherm. Res., 89, 57-64, 1999.

Markham, B. L. and J. L. Barker, Landsat MSS and TM post-calibration dynamic ranges, exoatmospheric reflectances and at-satellite temperatures, Landsat Technical Notes, 1, 3-8, 1986.

Matsushima, N., Geothermal activities in the summit crater of Iwodake volcano, Satsuma-Iwojima, Proc. Volcanic Structure in the Shallow Part and Volcanic Fluid, Disas. Prev. Res. Inst., Kyoto Univ., 125-138, 2001 (in Japanese with English abstract).

Mouginis-Mark, P. J. and P. W. Francis, Satellite observations of active volcanoes: Prospects for the 1990s, Episodes, 15, 46-55, 1992.

Ono, K., T. Soya, and T. Hosono, Geology of the Satsuma-Io-Jima District. Quad-rangle Series: Scale 1:50,000, 80 pp., Geological Survey of Japan, Tsukuba, 1982 (in Japanese with English abstract).

Rothery, D. A., P. W. Francis, and C. A. Wood, Volcano monitoring using short wavelength infrared data from satellites, J. Geophys. Res., 93, 7993-8008, 1988.

Sekioka, M. and K. Yuhara, Heat flax estimation in geothermal areas based on the heat balance of the ground surface, J. Geophys. Res., 79, 2053 2058, 1974

Sekioka, M., Y. Itoh, T. Saitoh, M. Ohba, and K. Takahashi, Measurements of heat discharge at Owakudani geothermal area, Hakone volcano, Japan, J. Jap. Geotherm. Energy Assoc., 15, 11-18, 1978 (in Japanese with English abstract).

Shinohara, H., W. F. Giggenbach, K. Kazahaya, and J. W. Hedenquist, Geochemistry of volcanic gases and hot springs of Satsuma-Iwojima, Japan: Following Matsuo, Geochem. J., 27, 271-285, 1993.

Shinohara, H., K. Kazahaya, G. Saito, N. Matsushima, and Y. Kawanabe, Degassing activity from Iwodake rhyolitic cone, Satstuma-Iwojima volcano, Japan: Formation of a new degassing vent, 1990-1999, Earth Planets Space, 54, this issue, 175-185, 2002.

Urai, M., Volcano monitoring with Landsat TM short-wave infrared bands: the 1990-1994 eruption of Unzen Volcano, Japan, Int. Jour. Rem. Sens. 21, 861-872, 2000.

USGS and NOAA, Landsat 4 Data Users Handbook, 86 pp., USGS, Alexandria, 1984

Vincent, R. K., L. C. Rowan, R. E. Gillespie, and C. Knapp, Thermalinfrared spectra and chemical analyses of twenty-six igneous rock samples, Rem. Sens. Envi., 4, 199-209, 1975. 